\title{
Climate and human development impacts on municipal water demand: A spatially-explicit global modeling framework
}

\author{
Simon C. Parkinson ${ }^{\mathrm{a}, \mathrm{b}, *}$, Nils Johnson ${ }^{\mathrm{b}}$, Narasimha D. Rao ${ }^{\mathrm{b}}$, Bryan Jones ${ }^{\mathrm{c}}$, Michelle T.H. \\ van Vliet ${ }^{\mathrm{d}, \mathrm{b}}$, Oliver Fricko ${ }^{\mathrm{b}}$, Ned Djilali ${ }^{\mathrm{a}, \mathrm{e}}$, Keywan Riahi ${ }^{\mathrm{b}, \mathrm{f}}$, Martina Flörke ${ }^{\mathrm{g}}$ \\ ${ }^{a}$ University of Victoria, Canada \\ ${ }^{b}$ International Institute for Applied Systems Analysis, Austria \\ ${ }^{c}$ City University of New York, United States \\ ${ }^{d}$ Wageningen University, Netherlands \\ ${ }^{e}$ King Abdulaziz University, Saudi Arabia \\ ${ }^{f}$ Graz University of Technology, Austria \\ ${ }^{g}$ University of Kassel, Germany
}

\begin{abstract}
Municipal water systems provide crucial services for human well-being, and will undergo a major transformation this century following global technological, socioeconomic and environmental changes. Future demand scenarios integrating these drivers over multidecadal planning horizons are needed to develop effective adaptation strategy. This paper presents a new long-term scenario modeling framework that projects future daily municipal water demand at a $1 / 8^{\circ}$ global spatial resolution. The methodology incorporates improved representations of important demand drivers such as urbanization and climate change. The framework is applied across multiple future socioeconomic and climate scenarios to explore municipal water demand uncertainties over the 21 st century. The scenario analysis reveals that achieving a low-carbon development pathway can potentially reduce global municipal water demands in 2060 by 2 to $4 \%$, although the timing and scale of impacts vary significantly with geographic location.
\end{abstract}

Keywords:

${ }^{*}$ Corresponding author. Email address: scp@uvic.ca

Preprint submitted to Environmental Modelling $\mathcal{E}$ Software

August 7, 2016 
Water demand, long-term planning, urbanization, climate change impacts, integrated assessment modeling, downscaling

\section{Introduction}

2

Global hydrological models (GHM) provide a virtual environment to explore the impacts of long-term development pathways on water resources and the effectiveness of policy [1-6]. As the quality and magnitude of water resources varies with geography, GHMs incorporating spatially-resolved water demand projections have been crucial in the assessment of future water challenges, such as resource scarcity and ecosystem quality [7, 8]. Municipal water systems extract and distribute water for direct use by the population and play an important role in the global hydrological cycle, representing 12 to $14 \%$ of total water withdrawn globally for human purposes in $2010[9,10]$. Most GHMs incorporating municipal water demand estimate average per capita trends at the national-level, and then downscale to a finer resolution by assuming national trends hold within countries $[4,6,9,11]$. Yet, historical observations suggest that per capita municipal water demand within countries varies spatially, mostly due to a combination of local climate conditions, economic status and urban form [12-15]. Furthermore, global models applied for future projections assume a static population distribution and are therefore unable to represent the sub-national spatial demand variability that will accompany projected urbanization.

Also less explored at the global-scale are the potential impacts of future climate change on municipal water demand. The direct climate sensitivity arises in the municipal sector from the freshwater used for municipal irrigation [12, 16-21]. Municipal irrigation includes water to support household and municipal landscaping (e.g., turf grass and gardens), and outdoor water features (e.g., swimming pools and fountains). Municipal irrigation represents more than $50 \%$ of total municipal water demand in many regions of the United States [13], and could play a key role in meeting future urban food requirements [22] and 
mitigating urban heat island effects [23]. Future variations in urban climate will affect water requirements of vegetation as well as the rate of evaporation from outdoor water features. Understanding the scale of climate change impacts on municipal water demand will provide insight into suitable adaptation strategy and the potential water co-benefits of global climate change mitigation policy.

The objective of this paper is to provide a new approach to developing long-term global municipal water demand scenarios. A spatially-explicit modeling framework is proposed that incorporates enhanced representations of human migration, economic development and climate sensitivity. The framework is applied across multiple future human development and climate scenarios to explore the impact of coupled climate-development trajectories on municipal water demand uncertainties over the 21 st century. The results provide important insight into model formulation and the potential water co-benefits in the municipal sector of policy targeting climate change mitigation.

\section{Methods}

\subsection{Overview}

Combined impacts of climate change and human development on municipal water demand are assessed at the global-level with the computational framework depicted in figure (1). The approach involves mapping per capita demand on a gridded representation of the earth's surface (i.e., a raster). The per capita water demand in each grid-cell is modeled as a function of a number of spatially-explicit indicators including projected income, population density, climate and historical observations. Per capita demand is then multiplied by spatial projections of population to estimate aggregate municipal water requirements in each grid-cell. The methodology utilizes spatially-explicit, quantitative interpretations of the most recent global change scenarios as a basis for the projections: the Shared So- 


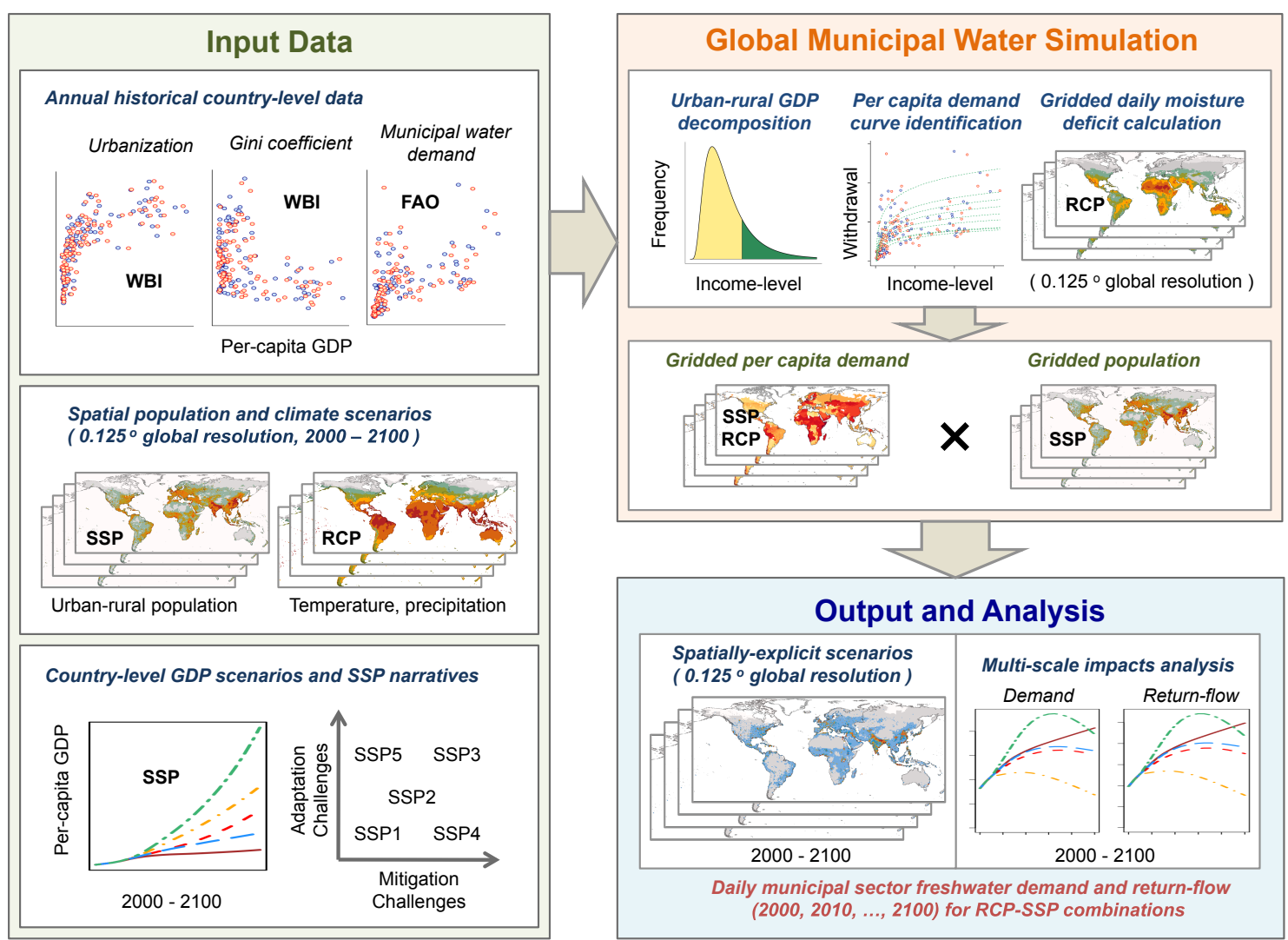
[25].

Figure 1: Framework for assessing global impacts of human development and climate change on municipal water demand. FAO = Food \& Agriculture Organization of the United Nations [26]. WBI = World Bank Indicators [27]. SSP = Shared Socioeconomic Pathway. RCP = Representative Concentration Pathway.

cioeconomic Pathways (SSP) [24], and the Representative Concentration Pathways (RCP) 
sectors in order to devise economic responses at scales relevant to water system transformations. The simulated water demands from the municipal sector will aid in the quantification of constraints on water availability for land-use and energy, which are the historical focus of global IAMs used to study climate change mitigation [29].

Demand scenarios are computed at a $1 / 8^{\circ}$ spatial resolution (grid cells approximately $14 \mathrm{~km} \times 14 \mathrm{~km}$ near the equator) and out to the year 2100 to align with the downscaled SSP and RCP datasets. The spatial resolution also ensures that parameterized demand sensitivities to population density are captured. Urban and rural populations are modeled separately in the framework to feature diversity in per capita demand stemming from differences in economic status, urban form and local climate conditions. A temporal downscaling approach enables generation of the demand scenarios at a daily time-scale. The daily time-scale is investigated to capture anticipated effects of changing socioeconomic and climatic conditions on extreme (peak) demand events important to water supply reliability [30]. Spatially-explicit validation of the modeling framework is currently limited due to the absence of suitable historical data. We alternatively calibrate the model to observed national data and use demand projections from other global models to evaluate the reliability of model results.

We use the term municipal water demand in this paper to refer to the volume of water that is needed in a particular location to fulfill useful end-use services in the municipal sector. We emphasize the definition here to differentiate the modeled water volumes from withdrawals, which often occur at locations other than end-use due to the reach of urban water infrastructure [8]. A separate analysis is required to parameterize corresponding scenarios for water supply e.g., with a hydro-economic model including investment decisions for alternative water supply options (reservoirs, wastewater recycling, desalination, etc.) [31, 32]. Hydro-economic models are able to quantify economic tradeoffs between upstream and downstream users, as well as economic impacts of conjunctive management 
of different sources. Future water prices can be simulated with a hydro-economic model and used to parameterize an expected response from municipal consumers [33]. In this context, the demand scenarios presented in this paper provide a useful reference point for analysis of additional responses to future water availability.

\subsection{Per capita demand}

\subsubsection{Income effects}

Previous studies highlight that as household income increases, demand for water from the municipal sector increases because part of this new income is spent on increasingly water-intensive end-uses [12, 15, 34]. However, as income continues to rise, per capita demand for water increases less proportionally, due to eventual saturation of useful services [2]. This suggests a non-linear relationship between household income and municipal sector water demand, and we propose an empirical model capturing these characteristics.

The lack of comprehensive consumer income and water use data makes identifying household-level models on a global-scale impractical. At the national-level, the Food \& Agriculture Organization of the United Nations (FAO) provides estimates of aggregate municipal sector water demand [26]. Concurrent observations of GDP are further available from organizations such as the World Bank [27]. Consequently, per capita GDP has been widely applied as a surrogate for average income in national-level municipal sector water demand models [2, 9, 11, 35-38]. Yet, the non-linear demand response to income changes expected at the household-level means consumers respond differently depending on their current income-level. Therefore, aggregating the response of households following nonlinear demand curves to average income changes should involve treatment of the income distribution [39].

The effects of income inequality are included in the demand model applied in this paper following the formulation proposed in [39]. The approach takes advantage of the 
observation that income distributions typically follow a log-normal shape [40]. Under the assumption of log-normality it is possible to consider average annual per capita demand $\Omega$ as a function of both per capita GDP $g$ and the variance of the income distribution $v$, by replacing the assumed arithmetic mean income (i.e., per capita GDP) with the geometric mean in a conventional semi-logarithmic demand model [39]:

$$
\Omega(y)=\alpha(y)+\beta(y) \cdot\left[\ln g(y)-\frac{v(y)}{2}\right]
$$

where $\alpha$ and $\beta$ are model coefficients, and $y$ denotes year. The Gini coefficient can be used to estimate the variance of the income distribution under the assumption of log-normality [41], and historical values are available for most countries [27]. A similar approach for municipal energy consumption utilized the Gini coefficient to project demands associated with different income quintiles [42]. In the approach applied here, when two countries with the same average per capita GDP are compared, the country with less income inequality will have the higher per capita water demand (i.e., aggregate demand elasticity with respect to income inequality is less than one). Previous analysis suggests the inclusion of the income inequality term has a relatively minor impact on demand levels; however, for longterm projections the effects of income inequality are likely important because of impacts on the rate of demand growth and interplay with long-term technological progress [39].

All parameters in (1) can be estimated for a number of countries in the base-year, making it possible to calculate the model coefficients at the national-scale using e.g., regression. Figure (2) depicts the results of a least-squares cross-sectional regression analysis utilizing data from 2000 and 2005 for 105 countries. The r-squared values are 0.56 and 0.55 respectively, and compare well with similar analysis of this dataset [37, 43]. Differences in the socioeconomic standing and consumption characteristics between urban and rural populations within countries are ubiquitous [44], and suggests the model should 


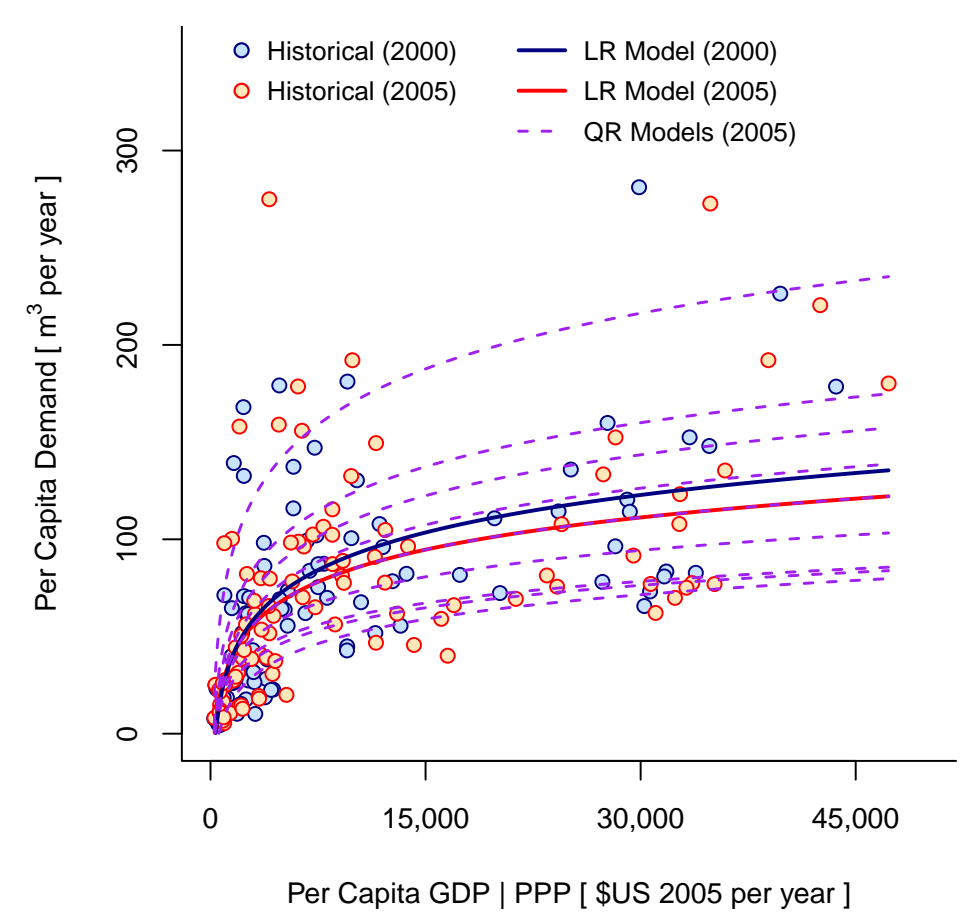

Figure 2: FAO Aquastat data for 105 countries, the results of the least-squares cross-sectional regression analysis for 2000 and 2005, and decile demand curves fit to the FAO Aquastat data for the year 2005. LR = least-squares regression; $\mathrm{QR}=$ quantile regression.

distinguish between population groups. We assume that in the base-year urban and rural populations within countries display different average income-levels but follow similar national demand curves (i.e., equivalent $\alpha$ and $\beta$ ). The national urban and rural demand curves are then calibrated based on gridded socioeconomic and climate indicators (section 2.3.1).

Cultural preferences and existing water policies (e.g., water price) represent other key determinants of municipal water demand [15], but are difficult to include in the modeling framework due to a lack of comprehensive global data. Previous analysis at the household level used agent-based models to integrate behavioral and social drivers of water demand [45]. Other global modeling approaches have incorporated water prices into the analysis 
by combining a number of separate country-level data sources [37]. These data sources often cover only part of a country's population, and include costs for wastewater treatment. Instead, the model in this study emphasizes a combination of path-dependency and long-term convergence at the national-scale to reflect inertia of the existing systems and associated policies and behaviors that impact long-term municipal water use, such as water pricing and cultural preferences.

The model accounts for path-dependency and the wide-range in observed historical per capita demands at the national-scale by identifying an ensemble of demand curves. The curves are estimated using quantile regression with (1). The quantile regression analysis specifies ten unique demand curves (or decile curves) representing the best fit solutions to ten equal increments of the cross-sectional data ordered from lowest to highest [46]. The decile curves fit to the FAO data for the year 2005 are also depicted in Figure (2). In the initial simulation year, countries are associated with a best-fit decile curve based on historical FAO data trends from 2000 to 2010. Countries lacking historical data are assumed to follow a regional average, with the regionalization following the breakdown used in similar previous global scenario modeling [47]. Convergence towards the identified decile curve is assumed over time using the following scaling factor:

$$
\gamma(y)=1+\gamma_{o} \cdot e^{-\lambda \cdot y}
$$

where $\gamma_{o}$ is the fractional difference between the base year observation, and the best-fit decile curve estimated with (1). The parameter $\lambda$ governs the convergence speed. By exploring the response to different convergence speeds and levels, as well convergence to alternative decile curves, the simulation framework can incorporate scenario-specific assumptions surrounding behavior and policy. For example, behavioral changes implicit in the scenario narrative (section 2.4) that are expected to reduce long-term water use inten- 
sity are represented in the framework by selecting a lower decile curve for convergence. The use of decile curves bounds the projections to lie within the historically-observed range of per capita demand intensities. Combining this constraint with the convergence rules enables a diverse number of plausible demand trajectories to be generated. The decile curves do not cover all possible future policy regimes, and therefore alternative demand trajectories outside the simulated range are a possibility.

\subsection{Technological change}

Technological change is a dynamic effect apparent in the long-term development of municipal water systems [9], and refers to the observed improvements in the efficiency of resource use caused by long-term technological innovation [48]. The emergence of technological change is represented in the demand curves by scaling the model coefficients $\alpha$ and $\beta$ in (9) by an annual improvement factor, with assumptions embedded in the scenario narratives (section 2.4). It is expected that technological change will occur most rapidly in countries that spend more on technology research, and historical spending levels typically correlate with income-level [27]. We reflect this quality using the sigmoid curve depicted in figure (3) to model accelerated technological change as an annual improvement in water intensity $\epsilon$ that increases with average income. The frontier technological change rate $\left(\epsilon_{\max }\right)$ is interpreted from previous long-term scenario studies [2, 9, 37], with the minimum rate $\left(\epsilon_{\min }\right)$ assumed to be half the frontier value. Curve parameters are updated in each simulation year to reflect changes in the global GDP distribution. Scenarios involv-

ing a reduction in between country income inequality therefore lead to harmonization of technological change rates in the model.

Technological change is calculated at the national-scale in each simulated year using 


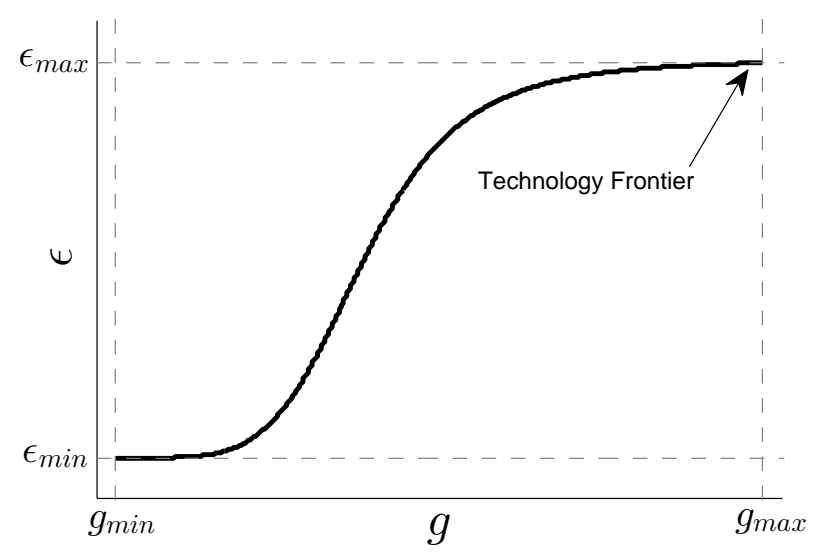

Figure 3: Graphical depiction of the implemented technology frontier approach to technological change, where $\epsilon$ is the compound annual efficiency increase and $g$ is per capita GDP.

188

the projected intensity improvements:

$$
\eta(y)=\prod_{t=1}^{y}[1-\epsilon(y)]
$$

where $\eta$ is the cumulative intensity improvement. Combining the path-dependency and technological change parameters yields the following form for the model coefficients:

$$
\alpha(y)=\alpha_{o} \cdot \gamma(y) \cdot \eta(y)
$$

$$
\beta(y)=\beta_{o} \cdot \gamma(y) \cdot \eta(y)
$$

where $\alpha_{o}$ and $\beta_{o}$ denote the coefficients identified in the base year using quantile regression with (1).

\subsubsection{Climate and population density}

Local climate conditions affect the amount of moisture needed to sustain vegetation grown in urban environments. Evaporative losses from swimming pools and fountains are 
also enhanced under increasingly arid conditions. The soil moisture deficit is an empirical hydro-climatic indicator describing the amount of freshwater needed to sustain moisture levels in a particular location, and is routinely applied to estimate irrigation requirements under data limitations $[49,50]$. Previous studies investigating the linkage between local climate and municipal water demand highlight the relationship between observed municipal irrigation and the calculated soil moisture deficit [12, 13, 16, 17, 51, 52]. Following the results of these previous studies, we integrate climate sensitivity into the global model by accounting for changes in the moisture deficit under alternative climate scenarios.

Initially, municipal irrigation demands $\Omega_{i}$ are disaggregated from the national demands estimated by (1). A parameter $\mu$ representing the fraction of total demand used for municipal irrigation is defined:

$$
\Omega_{i}(y)=\mu_{i}(y) \cdot \Omega(y)
$$

Previous observations suggest that $\mu$ increases with household income [12, 13, 53]. For example, survey of households in Eastern Africa show that municipal irrigation makes up a small fraction (about 1\%) of total water demand in very low-income rural households, whereas nearby urban areas able to afford piped access apply an average of $10 \%$ of total demand towards municipal irrigation [14]. Previous research in China and Brazil also identifies similar differences between the fraction of total demand used for municipal irrigation and income-level $[54,55]$. We model the observed income effect on municipal irrigation penetration with the sigmoid curve $\psi$ depicted in Figure (4a). The stylized curve increases from a minimum of $1 \%$, which occurs at the average per capita GDP estimated for rural Sub-Saharan Africa in 2010, to a saturation level at an average per capita GDP equivalent to the United States in 2010. The saturation level is calibrated based on geographical sensitivities to the moisture deficit observed in North America [13]. Specifically, we fit a linear function $\phi$ between the estimated annual average moisture deficit $m_{a}$ and ob- 
served municipal irrigation (Figure (4b)), and results compare well with similar analysis in Mayer et al (1999) [13]. Combining the income and climate sensitivity terms yields the estimated fraction of total demand used for municipal irrigation (i.e., $\mu=\psi \cdot \phi$ ).

Further spatial and temporal downscaling of the municipal irrigation demands is achieved by assuming proportionality with changes in the simulated daily moisture deficit. A similar approach to temporal disaggregation was proposed in [4], but was based on the monthly temperature distribution. A proportional relationship between changes in irrigation volumes and the moisture deficit was also previously used to estimate the impact of climate change on agricultural systems in the United States [20] and globally [50]. As the demand curves applied in this paper are calibrated from national-level averages, spatial variations in municipal irrigation due to climate are taken relative to the population-weighted mean annual moisture deficit $M_{o}$ :

$$
M_{o}=\frac{1}{N_{c}} \cdot \sum_{c}\left[\hat{p}\left(c, y_{o}\right) \cdot m_{a}\left(c, y_{o}\right)\right]
$$

where $c$ denotes grid-cell, $N_{c}$ is the number of grid-cells, $\hat{p}$ is the normalized population (i.e., grid-cell population divided by total national population), and $y_{o}$ is the first year in the simulation horizon. The population-weighted moisture deficit in the initial year is also used to estimate the maximum penetration of municipal irrigation (i.e., $\phi=\phi\left(M_{o}\right)$ ). This choice ensures a consistent representation of non-irrigation demands under varying climate. Spatial and temporal variations in municipal irrigation due to climate variability are reflected by the fractional change in the moisture deficit $\delta_{m}$ :

$$
\delta_{m}(c, y, t)=\chi(c, y) \cdot\left[\frac{m(c, y, t)}{M_{o}}-1\right]
$$

where $m$ represents the daily moisture deficit, and $t$ represents the sub-annual time-slicing 
(daily). A scaling factor $\chi$ is applied to the gridded daily moisture deficit to reflect reduced per capita irrigable area with increasing population density. This urban form effect has been observed e.g., in China, where municipal irrigation plays a minor role in dense urban areas [56], but is prevalent in lower income rural municipalities [54]. These observations contradict the assumed relationship between income and municipal irrigation, and follow from reduced availability of outdoor area in dense urban cities. We estimated an inverse sigmoid function $\chi=\xi(d)$, where $d$ is population density, to reflect the anticipated impacts of urban form on municipal irrigable area. The stylized curve is depicted in Figure (4c). Population density is calculated as the total grid-cell population divided by the raster gridcell area. Assuming the non-irrigation demand is spread evenly across the population and year, the following functional form for per capita municipal water demand $\omega$ is obtained at the grid-scale:

$$
\omega(c, y, t)=\Omega(y) \cdot\left[1+\mu_{i}(y) \cdot \delta_{m}(c, y, t)\right]
$$

We calculate the moisture deficit at the daily time-scale as the difference between potential evapotranspiration $v$ and effective precipitation $e$ :

$$
m(c, y, t)=v(c, y, t)-e(c, y, t)
$$

Effective precipitation is calculated following the methodology described in [49] and [50], and the modified daily Hargreaves method is used to calculate potential evapotranspiration [57]. Evapotranspiration rates vary across vegetation types, although we currently assume a constant vegetation index due to a lack of historical urban vegetation data at the globalscale.

The proposed methodology represents a simplified way of modeling climate and urban form sensitivities. Basing the response of municipal irrigation on changes in the moisture 

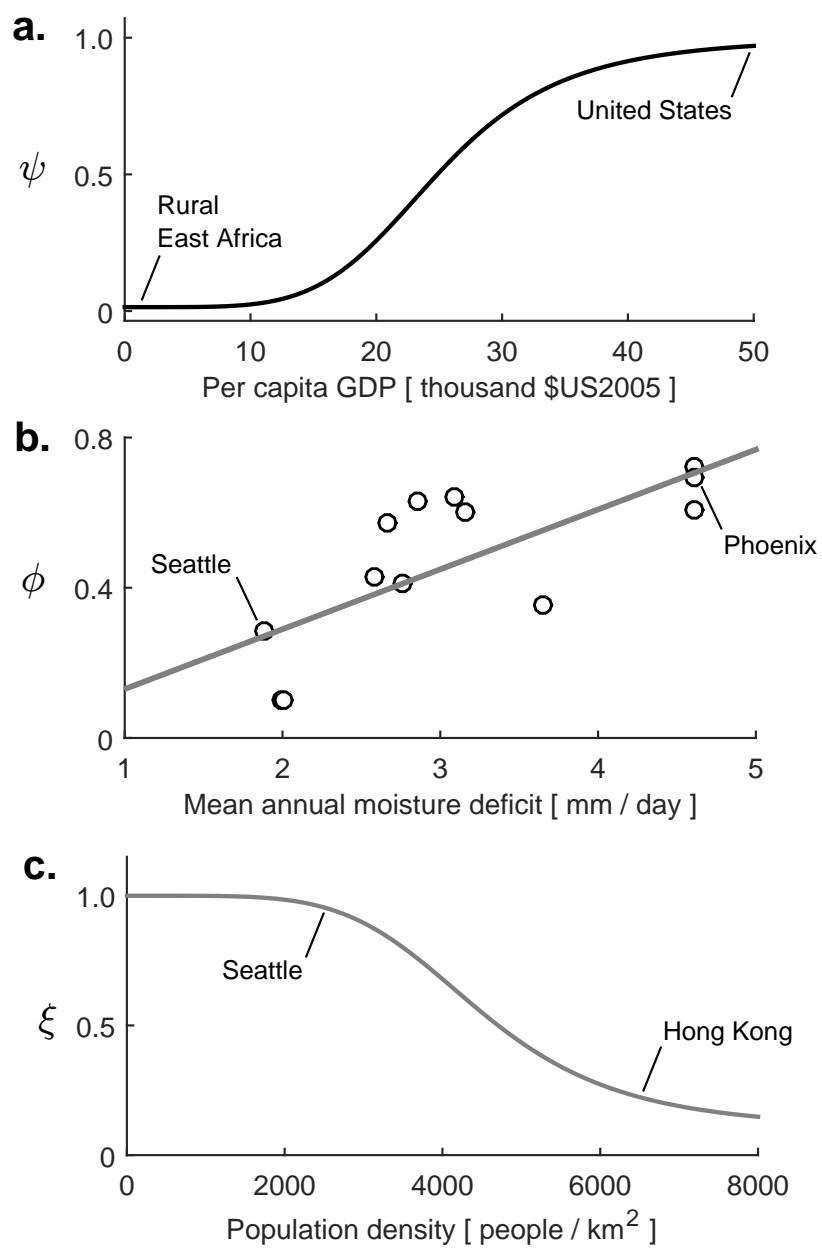

Figure 4: Stylized models for representing demand sensitivities to climate and urban form: a. Municipal irrigation utilization $(\psi)$ as a function of per capita GDP; b. Maximum penetration of municipal irrigation into national demand $(\phi)$ as a function of mean annual moisture deficit, and observed values for a number of cities in North America [13]; and c. Municipal irrigable area indicator $\xi$ as a function of population density. 
deficit is somewhat analogous to the use of heating and cooling degree days in the estimation of climate change impacts on the municipal energy sector [58]. There are a number of limitations, including uncertainties surrounding assumptions that municipal irrigation demands scale linearly with changes in the moisture deficit. Detailed physical modeling will provide a more accurate representation of the water impacts of urban form [59], but is currently too data intensive to consider in global-scale analysis. The lack of irrigated vegetation in dense urban areas is also a contributor to the urban heat island effect [23], and the current version of the model does not account for impacts of urban irrigation on local climate conditions.

\subsubsection{Return-flow}

The return-flow from the municipal water sector provides an indication of the potential wastewater volume produced over a given timeframe. Following previous studies [9] the return flow is quantified by subtracting consumptive demand (the amount of water demanded that will not be returned to the source) from total demand. Consumptive demand is estimated with country-level efficiencies taken from the WaterGAP model [9]. The consumption efficiencies are then assumed to converge towards a maximum of $92 \%$ under the process of long-term technological change. The maximum possible efficiency is meant to represent constraints on the amount of municipal water that must be consumed (e.g., for transpiration and other evaporative losses), and is selected based on the highest observed historical level [9]. Convergence rates align with assumptions for supply efficiency, and are described in greater detail in the following section.

\subsection{Human development scenarios}

The shared socioeconomic pathways (SSP) represent the most recent socioeconomic scenarios implemented in long-term global change modeling. The scenarios consist of qualitative narratives and quantitative projections for economic growth, technology, and 
demographic characteristics, and are specifically tailored to span the range of expected challenges faced when mitigating and adapting to climate change [24]. The five SSP narratives are briefly described below, with a detailed description provided in [60].

- SSP1 (Sustainability): The world transitions towards a more sustainable path, with specific focus on the environment. Population growth is low, economic development is high, and inequalities decrease both between and within countries.

- SSP2 (Business-as-usual): Countries proceed on a social, economic, and technological pathway that follows historical patterns. Population growth and economic development is in the mid-range of the projections.

- SSP3 (Regional rivalry): Countries increasingly focus on domestic and regional issues. Economic development is slow, consumption is material-intensive, and inequalities persist or worsen over time. Population growth is low in high-income countries and high in emerging countries.

- SSP4 (Inequality): Inequality worsens both within and between countries. Economic growth is moderate in high-income and middle-income countries, while lowincome countries lag behind. Global population growth is moderate, driven by high fertility in emerging countries.

- SSP5 (Fossil fueled development): The world transitions toward a more fossil fuel intensive path, with relatively little action on avoiding potential global environmental impacts, due to a perceived tradeoff with economic development. Global population growth is low, driven by reduced fertility in the developing world, economic development is high, and inequalities reduce both between and within countries.

The SSP narratives provide important guidance on assumptions surrounding technological change, behavior and income inequality. For example, the conditions expected in 
SSP1 are likely to translate into sustainable and inclusive water development strategies. The focus on sustainability is expected to drive rapid technological change that combined with long-term behavioral shifts, would lead to long-term reductions in per capita municipal water demand. Conversely, limited concern and action on issues in SSP5 is expected to correlate with widespread increases in per capita intensity, although rapid technological change accompanying high-income levels will help to offset increased supply requirements.

Table (1) summarizes the translation of the SSP narratives to the model parameterization. Convergence towards different demand curves is stipulated to reflect the differences in behavior and policies implicit in the SSP narratives. For example, sustainable enduse behavior and policies assumed in SSP1 are simulated by having countries converge towards one of the lower decile curves. Following [47], we further utilize the scenario narratives to disaggregate urban-rural average income trajectories, by assuming income convergence to different levels at different rates (Appendix A). For instance, to reflect inequalities implicit in the narratives, urban-rural incomes in SSP3 and 4 are assumed to converge the slowest.

The quantitative SSP data applied in this work includes the GDP and population projections for 184 countries. Population projections come from the Wittengenstein Centre for Demography's long-term population model, which generates national-level population estimates out to 2100 based on assumptions surrounding future age, sex and educational composition [61]. Urbanization dynamics have also been estimated under SSP-specific assumptions surrounding urbanization rates [62]. National-level GDP scenarios (in purchasing power parity) come from the Organization for Economic Co-operation and Development's (OECD) Environmental Growth model, which is based on a convergence process and places emphasis on the following key drivers: population, total factor productivity, physical capital, employment and human capital, and energy resources [63]. 


\begin{tabular}{llllll}
\hline \multirow{2}{*}{ Parameter } & \multicolumn{5}{l}{ Socioeconomic Scenario } \\
& SSP1 & SSP2 & SSP3 & SSP4 & SSP5 \\
\hline Per capita demand decile curve & 30 th & $30-70$ th & $50-90$ th & $40-90$ th & 90 th \\
Frontier technological change rate & $1.00 \%$ & $0.50 \%$ & $0.25 \%$ & $0.25 \%$ & $1.00 \%$ \\
Urban-rural IR convergence level & $5 \%$ & $10 \%$ & $20 \%$ & $20 \%$ & $5 \%$ \\
National Gini convergence level & 0.25 & - & 0.60 & 0.60 & 0.25 \\
Convergence year & 2110 & 2120 & 2130 & 2130 & 2110 \\
\hline \hline
\end{tabular}

Table 1: Translation of the qualitative SSP narratives to the quantitative water modeling parameterization. For per capita demand decile curves, entries with a range in values indicate divergence across countries. For example, in SSP4 developing economies converge to a lower decile curve, with advanced economies converging to higher levels. Technological change rates are estimated from [9] and [37]. Urban-rural income ratio (IR) convergence modeled after [47]. Decile curve and Gini convergence are interpreted from the SSP narratives. For SSP2, the Gini coefficients remain at the estimated 2010 level over the projections.

Spatial population scenarios are a key component of the analysis, and we apply the dataset described in [64] to represent the national-level urban and rural population projections at a $1 / 8^{\circ}$ spatial-scale. The downscaling approach applied in [64] utilizes a gravity-based population model to capture important spatial effects of urbanization, including densification and urban sprawl. Further improvements over previous approaches include refined treatment of protected areas and boundary effects [65]. The spatial population scenarios are a potential source of uncertainty, as small area (grid-cell) projections of long-term population change are subject to a variety of assumptions regarding vital rates, migration, as well as population response to the socio-economic drivers of spatial change. The GDP pathways are also broken into urban and rural components and downscaled to the corresponding $1 / 8^{\circ}$ spatial-scale following the procedures described in Appendix A.

\subsection{Climate scenarios}

For climate, we utilize the most recent scenarios applied in the global climate modeling community, the RCPs [25]. Downscaled, bias-corrected ensemble results from five global 
climate models participating in the Coupled Model Intercomparison 5 (CMIP5) project are included in our analysis [66, 67]: MIROC-ESM-CHEM, IPSL-CM5A-LR, HadGEM2ES, NorESM1-M and GFDL-ESM2M. The downscaled data was obtained from the Intersectoral Impacts Model Intercomparison Project (ISI-MIP) database ${ }^{1}$ [68]. These data are generated at a $1 / 2^{\circ}$ spatial-scale, and we downscale to $1 / 8^{\circ}$ using bi-linear interpolation. We decided to utilize this simple downscaling approach to enable better treatment of the effects of population density at the $1 / 8^{\circ}$ spatial scale, which would be less pronounced if the population data was aggregated to $1 / 2^{\circ}$. Challenges associated with developing higher resolution downscaled climate parameters for projecting hydrologic indicators is discussed recently in [69], and overcoming these challenges is beyond the scope of this paper.

\section{Results}

This section presents key results of the global assessment, with specific focus on spatial, temporal, and scenario-specific dimensions of the analysis. We initially assess the relative importance of socioeconomic drivers by exploring results sensitivity to the SSPs. Effects of non-stationary climate conditions are then incorporated by examining results under SSP-RCP scenario combinations.

\subsection{National-level}

Figure (5) depicts the modeled urban and rural demand curves obtained at the nationallevel under stationary base-year climate for a sample of eight representative countries. The national demand curves trace the per capita water demand as a function of per capita GDP (income) over the simulation horizon (2000 to 2100). Municipal water demand in emerging economies (China, India, Egypt, Nigeria and Brazil) initially increases rapidly

\footnotetext{
${ }^{1}$ The data is produced up to 2099 , and to simplify the modeling we assume these conditions hold in the year 2100.
} 
across all scenarios due to high elasticity at low-incomes. The model projects relatively steady per capita demand in developed economies (Germany, US, and Japan) across most scenarios due to the assumed saturation of useful water services at high-income levels. Base year per capita demand in Germany is relatively low compared to other advanced economies, and as the SSP5 scenario is parameterized to converge towards the 90th percentile global trend curve, significant demand growth occurs in Germany in this scenario. Conversely, the sustainability-oriented behavioral and policy changes assumed implicit in the SSP1 narrative lead to significant reductions in per capita water demand across all nations (convergence towards the 30th percentile global trend curve), with the results particularly prevalent in the US, which currently experiences some of the highest per capita demand levels globally.

Technological change is included in the results depicted in Figure (5), and helps offset increases in water demand with increasing incomes. The impacts are most prevalent in SSP1 and 5, where a reduction in water demand intensity can be seen as countries transition to higher income-levels. Lower technological change rates occur in SSP3 and 4. These differences affect the long-term trajectory in the US, where per capita demands excluding technological change in SSP4 and 5 are similar but diverge significantly when technological change is considered. The GDP downscaling procedure places more wealth in urban areas, with the effects observed in the results as a difference between the urban and rural trajectories in the base year. Rural per capita demands are observed to exceed urban demands at similar income-levels because rural technological change lags behind urban areas based on the parameterized relationship with income-level. In SSP1 and 5, the urban-rural incomes converge more quickly, both within and between nations, leading to similar end-of-century per capita demands globally. Alternatively, in SSP3 and 4, where the most inequality is assumed, the trajectories remain more divergent over the simulation horizon. 


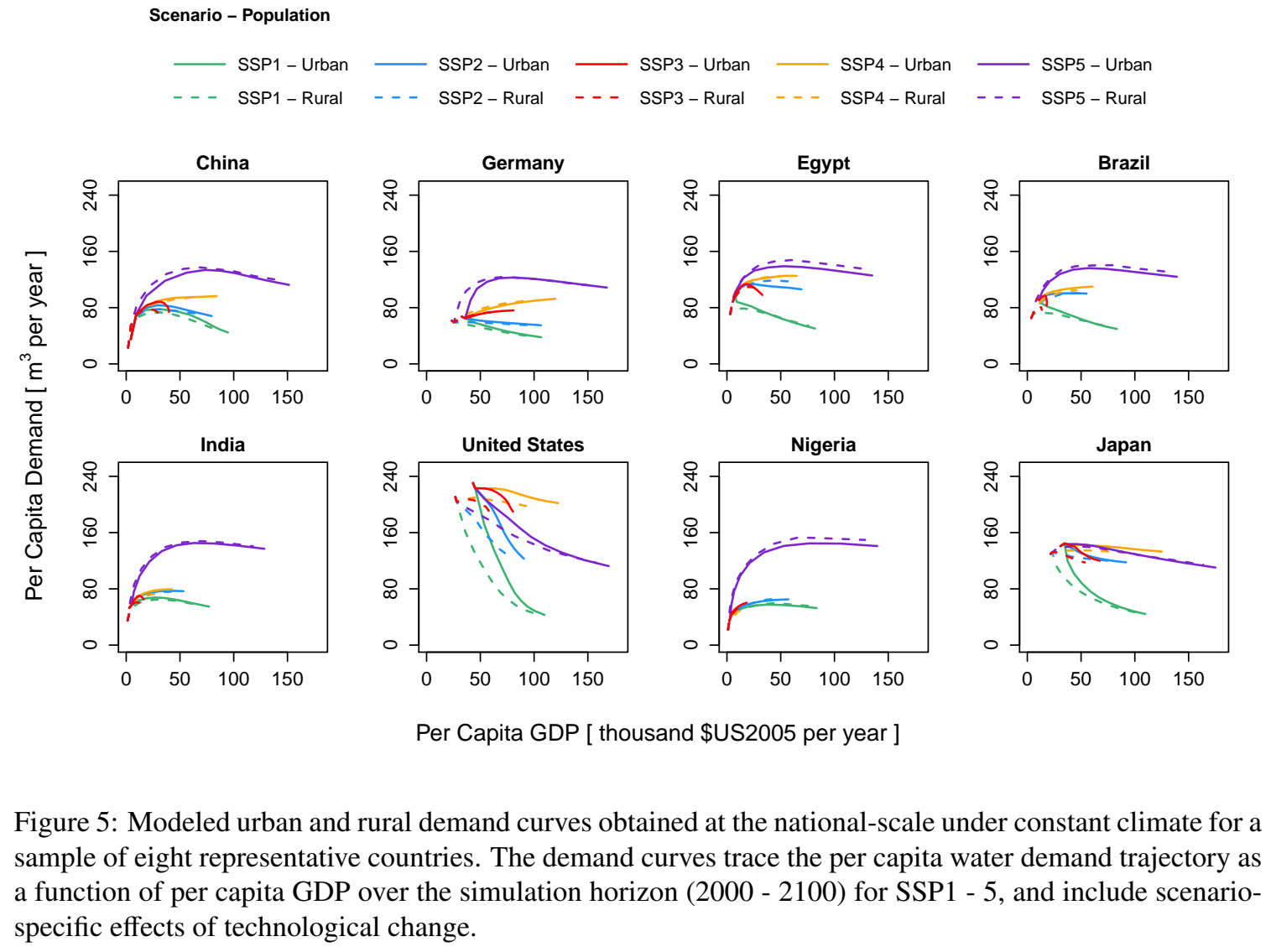




\subsection{Grid-level}

The demand curves estimated at the national-scale are downscaled to the grid-level with Eq.(9). Results of the spatially-explicit analysis are summarized in Figure (6). Depicted is the mean annual municipal water demand across the SSPs, in the years 2010, 2040 and 2070, under stationary base-year climate conditions. The most significant growth in municipal sector water demand is anticipated to occur between 2010 and 2060, and to take place mainly in South Asia, China, and Sub-Saharan Africa. Economic growth is projected in these regions across many of the SSPs [63], which under the identified demand model (high elasticity at low-incomes), significantly increases per capita water demand. Concurrent to the economic development is an increasing population, which is expected to peak in these regions across most scenarios (excluding SSP3) around 2070 [61]. A combination of reduced fertility rates and saturation of useful municipal water services occurs as urban areas transition towards higher income-levels, and leads to long-term reductions in per capita demand.

Further mapped in Figure (7) is the coefficient of variation $(\mathrm{CoV})$ calculated across the SSPs as the maximum range divided by the mean. The spatial distribution largely follows country delineation due to the parameterized national demand curves. The largest variability occurs in locations with a combination of uncertainties surrounding both demand intensity and population. For example, variability is particularly prevalent in the Tibetan Plateau region of Southwest China mainly due to uncertainties surrounding urbanization levels and its effect on the distributed rural population in this region. Most locations display a range of results across the SSPs that is greater than the ensemble mean value (i.e., $\mathrm{CoV}>1$ ), indicating a high-degree of sensitivity to socioeconomic uncertainties. As expected, much more uncertainty surrounds end-of-century conditions compared to mid-century conditions.

Scenario-specific results are highlighted for Nigeria in Figure (7). The economic 
a.
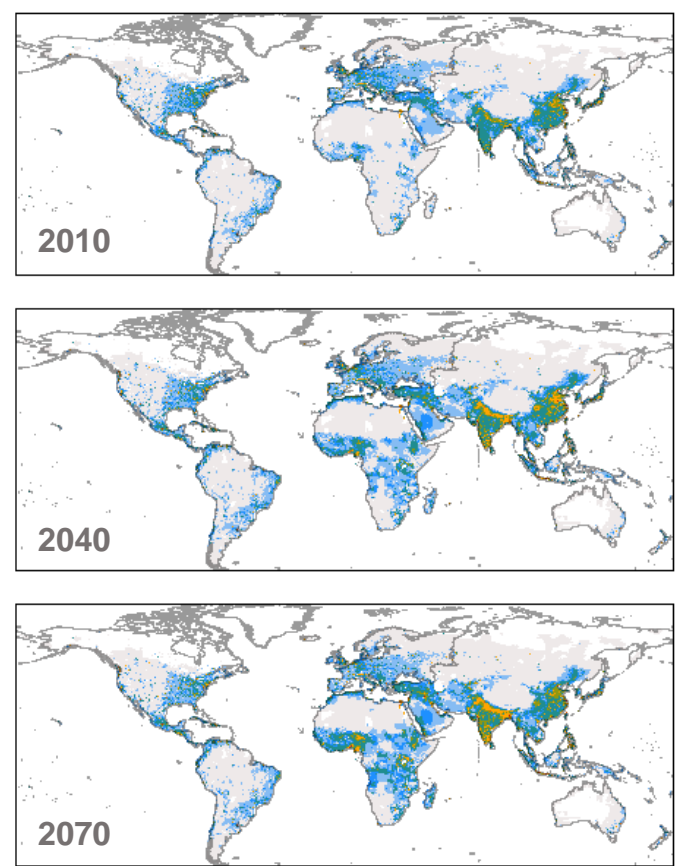

Demand [ million $\mathbf{m}^{3}$ per year ]

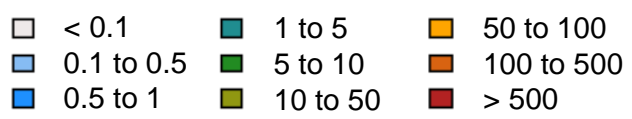

b.
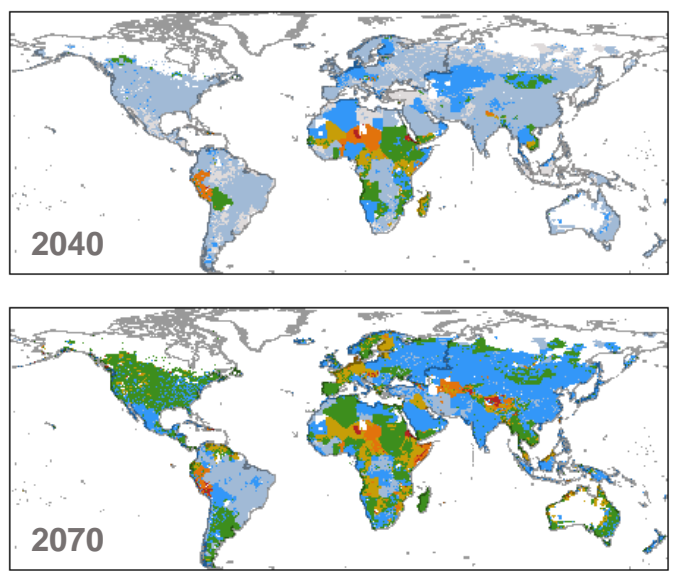

Coefficient of Variation

$\begin{array}{lll}\square<0.25 & \square 0.75 \text { to } 1 & \square 1.5 \text { to } 2 \\ \square 0.25 \text { to } 0.5 & \square 1 \text { to } 1.25 & \square 2 \text { to } 3 \\ \square & 0.5 \text { to } 0.75 \text { व } 1.25 \text { to } 1.5 & \square>3\end{array}$

Figure 6: Mean and coefficient of variation $(\mathrm{CoV})$ of the spatially-explicit global municipal water demands obtained across the SSPs. In the calculation of the CoV, we utilize the maximum range across the scenarios divided by the mean value. 
growth and urbanization projected for this emerging African economy across the SSPs results in rapid growth in urban water demands across all scenarios. The SSP5 scenario displays the most growth due to the assumed transition towards water-intensive societies and the scale of the projected GDP expansion relative to the other SSPs. Conversely, the sustainability-oriented policy and behavioral measures expected in SSP1 lead to significantly lower water requirements. SSP2 and 3 display somewhat similar demand patterns, but the per capita demand in SSP3 is less due to slower income growth. In the end, the reduced per capita usage in SSP3 ends up being offset by increased population. Similar results are obtained for other emerging economies throughout Sub-Saharan Africa, as well as in Latin America and Asia.

\subsection{Global}

Aggregating the water requirements at the grid-scale yields an estimate of total global municipal water demand. Annual results are presented in Figure (8), along with the calculations for consumption and return-flow. In SSP1 we find that by 2070, global municipal water use reduces compared to current levels. The largest reductions are expected in consumptive demand due to a combination of improved supply and end-use efficiencies. At the high-end of the projections, we find that SSP3 and 5 lead to end-of-century requirements more than doubling from the current level. Peak water demand is expected to occur in SSP5 in the year 2070, and represents a municipal water requirement nearly three times the current level. Results from three similar models for the SSP2 socioeconomic scenario are also depicted in Figure (8). Our assessment appears to yield a global estimate for SSP2 that compares well with the H08 model [11, 70], but is lower than the WaterGAP [70] and PCR-GLOBWB [4] models, as well as a similar business-as-usual scenario explored with the GCAM model [37]. 


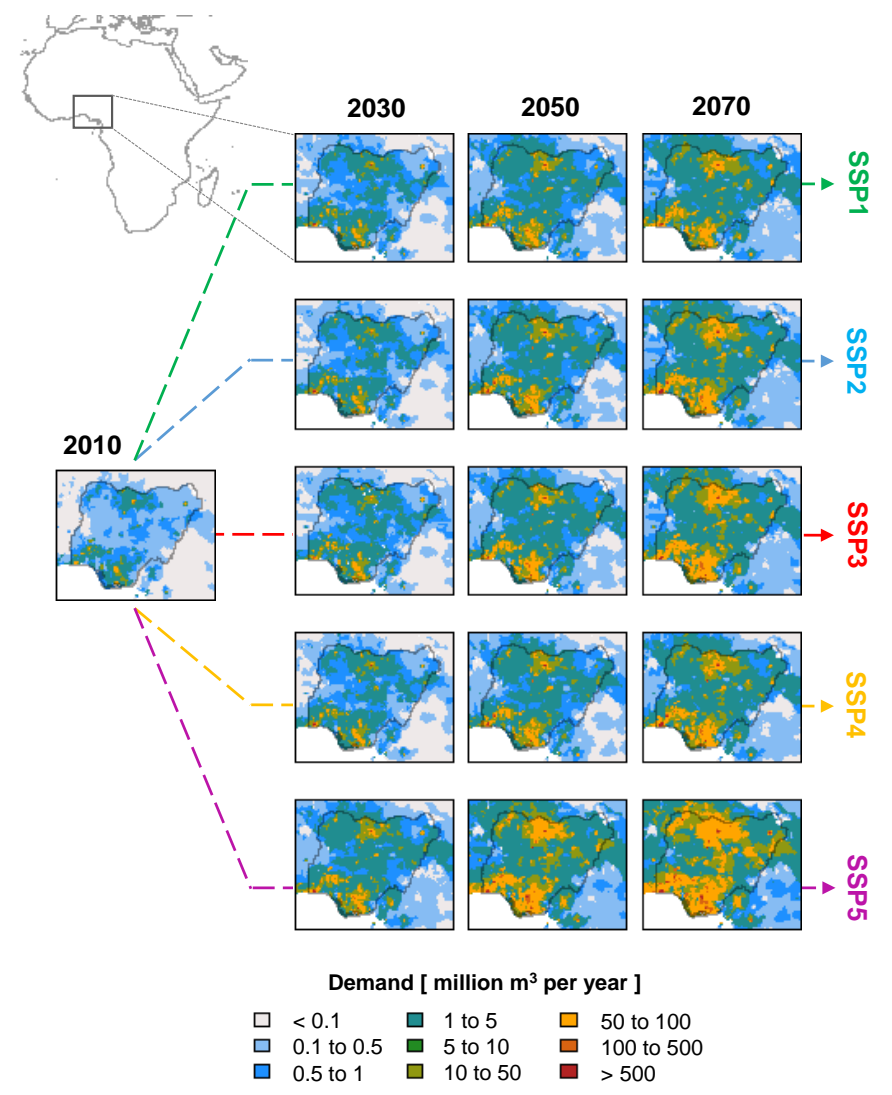

Figure 7: Spatially-explicit municipal water demand scenarios for Nigeria across the SSPs. 


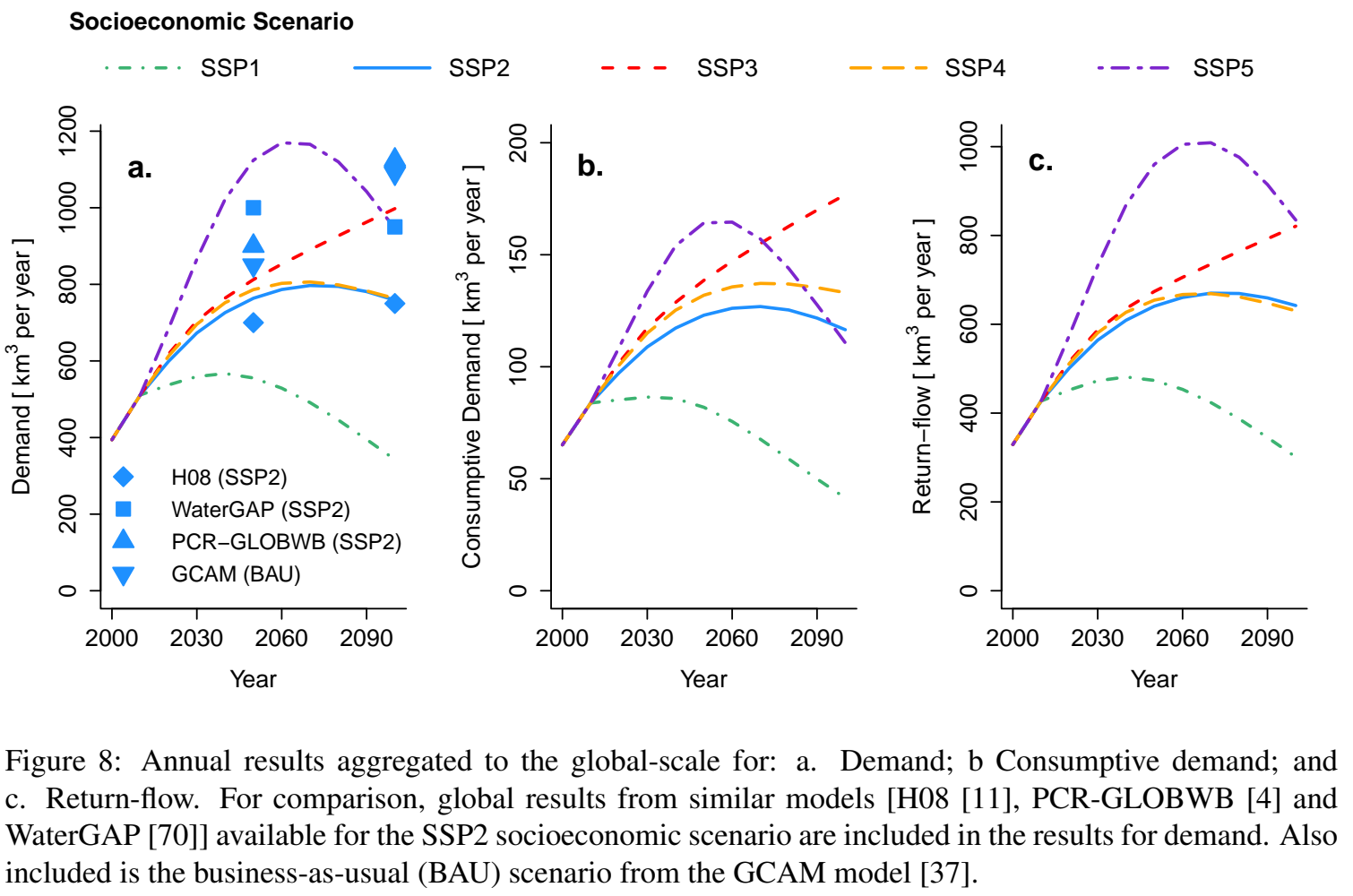




\subsection{Impacts of climate change}

We focus on the municipal water implications of the RCP2.6 and 8.5 climate scenarios to capture the largest range of uncertainties in radiative forcing under future greenhouse gas emissions. The RCP8.5 scenario represents a fossil fuel intensive global development pathway that results in an increase in end-of-century radiative forcing of $8.5 \mathrm{~W} / \mathrm{m}^{2}$ relative to pre-industrial levels and extreme climate change [71]. The RCP2.6 scenario represents a low-carbon development pathway associated with a $2.6 \mathrm{~W} / \mathrm{m}^{2}$ increase in radiative forcing and a high probability of limiting global mean temperature change over the 21 st century to $2^{\circ} \mathrm{C}$ [72]. The use of the extreme climate scenarios restricts the socioeconomic scenarios that can be explored to SSP3 and 5, as these are the only cases likely to produce emission pathways consistent with a 2.6 and $8.5 \mathrm{~W} / \mathrm{m}^{2}$ radiative forcing. Even SSP3 may be incapable of providing the economic input commensurate with a $8.5 \mathrm{~W} / \mathrm{m}^{2}$ world; nonetheless, we decided to analyze the pathway to explore the different challenges to adaptation with SSP5.

\subsubsection{Average and peak demand}

To highlight the vulnerability of municipal water supply systems to climate change, we examined impacts to both average and peak daily demand requirements. The peak daily requirements are closely related to the required capacity of water supply and distribution infrastructure, and are therefore an important aspect of long-term planning. We estimated the peak daily water demand in each grid-cell as the 95th percentile of the annual timeseries. The long-term response of the climate to different emission pathways means the climate scenarios vary little until mid-century [25], and to capture these longer-term effects while accommodating uncertainties surrounding the long-term evolution of the climate system, we focus on the average impacts obtained over the 2050 to 2080 period.

Figure (9) depicts the mapped difference in global municipal water demand between 
RCP8.5 and RCP2.6. In most locations, RCP8.5 (extreme climate change) results in relatively modest increases in average annual municipal water demand, although in some instances (e.g., Indonesia), demand in fact decreases. This decrease is due to wetter conditions in RCP8.5 reducing the need for municipal irrigation. Spatial precipitation patterns vary significantly across climate models, and will affect the results depending on the selected model (in this case we used the ensemble). The analysis suggests that achieving the RCP2.6 scenario (minimum climate change) would reduce aggregate annual global municipal water demand in comparison to the RCP8.5 scenario (maximum climate change) by $2 \%$ in the SSP3 scenario, and by $4 \%$ in the SSP5 scenario.

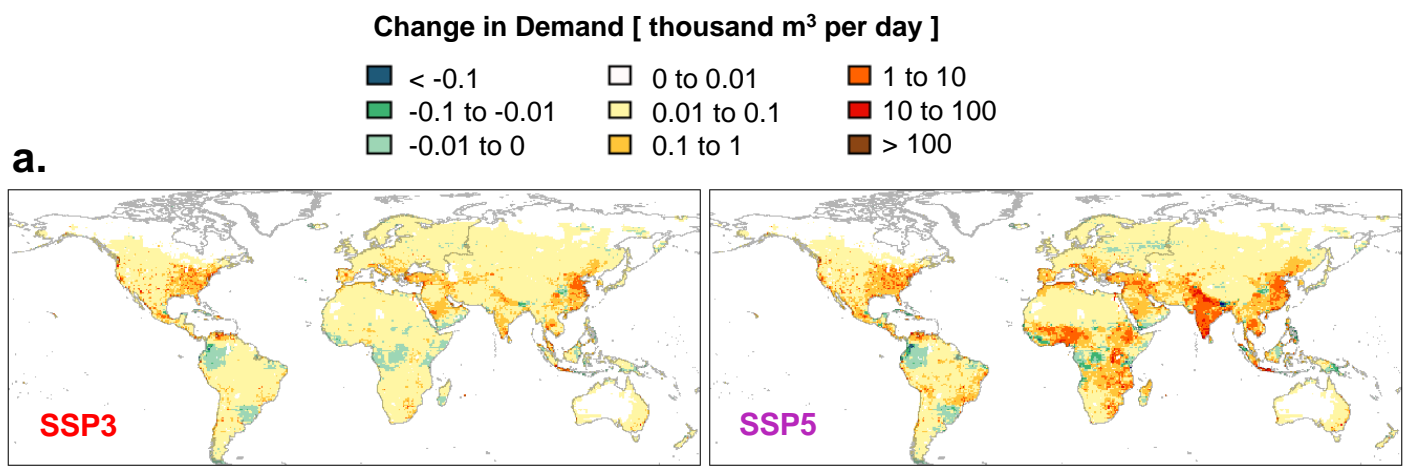

b.

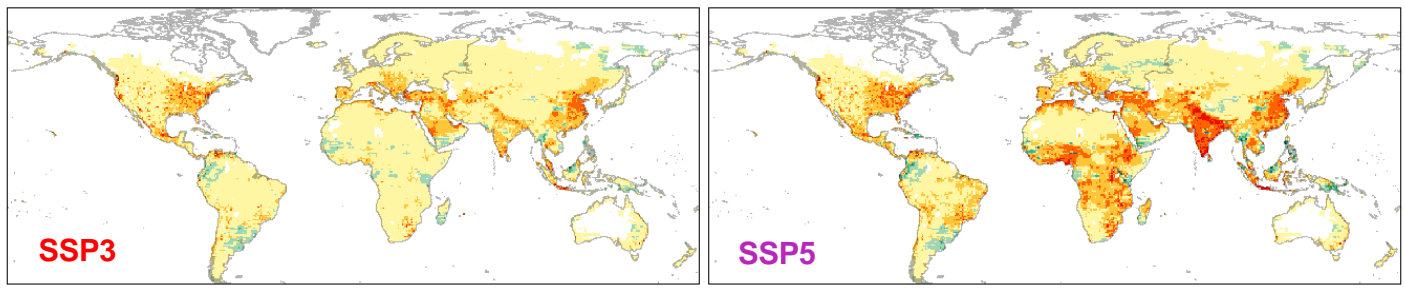

Figure 9: Mapped change in municipal water demand in RCP8.5 relative to RCP2.6. The changes are averaged over the 2050 to 2080 period. a. Annual average demand; and b. Peak daily demand.

Benefits of climate change mitigation (i.e., achieving RCP2.6 opposed to RCP8.5) 
differ spatially. Figure (10) depicts the percent change in average and peak demand for SSP3 and 5 as a cumulative spatial distribution calculated across inhabited grid-cells. The change is calculated relative to results obtained under static base-year climate conditions. We find that in the RCP8.5 scenario that $95 \%$ of locations experience a change in average demand between -1 to $10 \%$, and a change in peak demand between 0 to $12 \%$. More than half of inhabited grid-cells in the RCP8.5 scenario see an increase in peak daily demand of $4 \%$. The range in climate impacts is reduced substantially in the SSP3 scenario: 95\% of locations experience both peak and average demand increases of only 0 to $6 \%$, with a mean value of less than $1 \%$. Similar distributions are obtained when the gridded impacts are weighted by population.

\section{Discussion and conclusion}

The municipal water sector provides crucial services for human well-being and will experience significant growth under the projected socioeconomic change in many regions globally. The municipal water sector is also directly vulnerable to the effects of climate change due to the large volumes of water used for municipal irrigation. This paper has assessed, for the first time, coupled climate-development impacts on global municipal water demand. A new modeling framework incorporating enhanced representations of human migration, income inequality, population density and climate sensitivity was developed for this task. The framework was applied to generate global municipal water demand scenarios over the 21 st century aligned with the most recent global change scenarios at a $0.125^{\circ}$ spatial resolution.

Model results suggest that socioeconomic changes will be the most important driver of shifts in future municipal water demand, with a wide range in outcomes obtained across the scenarios investigated. The least water-intensive scenario (SSP1) results in global municipal water demand decreasing at an average rate of $0.1 \%$ per year over the 21 st century, 

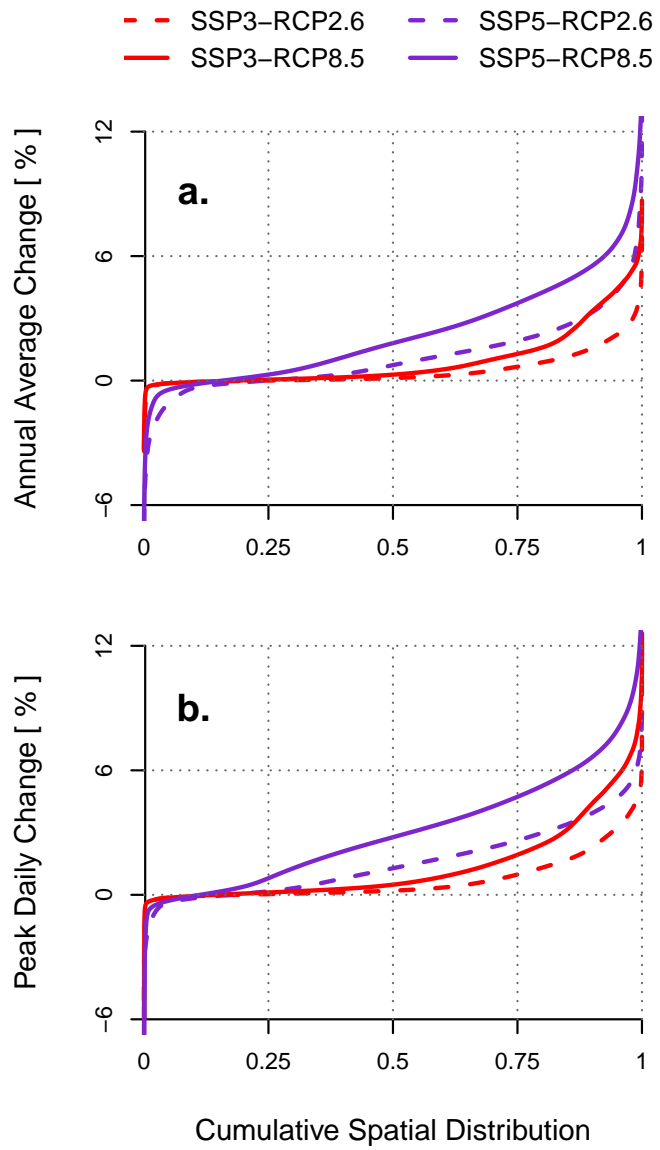

Figure 10: Spatial distribution of climate change impacts on municipal water demand over the 2050 to 2080 period. The change is calculated relative to the results obtained under stationary baseyear climate conditions, and is averaged across the three decades. a. Annual average demand and b. Peak daily demand. 
whereas the most water-intensive case (SSP5) results in demands increasing at a rate of $0.9 \%$ annually. All scenarios investigated involve rapid demand growth in urban areas of emerging economies ( 0.7 to $1.7 \%$ increase per year), whereas demand-levels in highincome regions remain relatively constant or decrease (-0.7 to $0.5 \%$ increase per year). The scale of growth and levels of uncertainty observed across the results for emerging economies suggest a critical need for infrastructure development strategies that incorporate long-term flexibility.

Climate sensitivities were incorporated into the global modeling framework using an empirical hydro-climatic metric encapsulating local water availability (the moisture deficit). Results obtained under non-stationary climate conditions suggest that half of all inhabited locations may experience peak municipal water demands 2 to $4 \%$ higher under a fossil fuel intensive global emission scenario (RCP8.5) relative to demand consistent with the emission scenario displaying a high probability of stabilizing global mean temperature change over the 21 st century at $2{ }^{\circ} \mathrm{C}(\mathrm{RCP} 2.6)$. The outcome means there are moderate freshwater co-benefits of climate change mitigation policy anticipated in the municipal sector that are additional to estimates from previous integrated assessments.

Comparing the non-stationary climate results across the SSP3 and 5 socioeconomic scenarios indicates that in terms of municipal water demands, SSP5 is much more vulnerable to the effects of climate change. Differences between the scenarios are largest in Sub-Saharan Africa and India. These results follow from the assumptions surrounding sensitivity of municipal irrigation to both changes in climate and socioeconomic development. In SSP3, slower income growth in emerging economies result in less municipal irrigation and therefore lower climate sensitivity, whereas in SSP5, rapid income growth results in a higher-penetration of municipal irrigation and therefore increased climate change vulnerability. Although the population in SSP5 appears more vulnerable than in SSP3, it is better equipped for adaptation due to significantly higher-incomes and less inequality. 
Systematic validation of the modeling framework is currently limited by our ability to test its long-term performance due to the absence of spatially-explicit historical data. Global results were compared with four similar modeling frameworks harmonized to similar national data-sets, and it was found that our calculations fall on the low-end of previous estimates. The reason is likely due to the semi-logarithmic form assumed in the demand model, and what this implies for demand elasticity at higher-incomes. Incorporation of income distribution effects in the model developed in this paper also leads to reduced demand projections, due to the impact on perceived average income-level in the aggregated household demand model. Overall, the income-demand relationship has a strong impact on the results, and this causal link could in fact be less pronounced. Other local drivers, such as institutional stability, cultural trends, policies and infrastructure could not be taken into account due to lack of globally comprehensive data sets. These areas are important for future work aiming to explain a greater range of the historical data.

\section{Appendix A. GDP downscaling}

National GDP projections are initially disaggregated into urban and rural average incomes in the base-year (2010). We make the assumption that per capita GDP in purchasing power parity is equivalent to per capita income at the national-scale. The national per capita GDP is then related to the urban and rural components through the following relationship:

$$
g_{n}=u \cdot g_{u}+(1-u) \cdot g_{r}
$$

where $u$ is the urbanization rate (fraction of national population that is urban), $g_{n}$ is average per capita GDP (income) across the national population, and $g_{u}$ and $g_{r}$ denote the urban and rural values respectively. The GDP projections are disaggregated into the urban and rural components following the procedure described in Grübler et al. (2007) [47]. The approach 
relies on the observation that residents in urban areas typically have higher incomes [44]. To reflect the income inequality between urban and rural populations, we take advantage of the fact that income is typically distributed lognormally across a population [40], and that in the base-year (2010) the top income quintile (i.e., top 20\%) always resides in urban areas [47].

We identify the average per capita GDP of the national income quintiles using the income Lorenz curve $L$. The Lorenz curve is estimated based on the shape of the lognormal distribution [41]:

$$
L(x)=\Phi\left[\Phi^{-1}(x)-\sigma\right]
$$

where $x$ is the percentile associated with a given income quantile, $\sigma$ is the standard deviation of the income distribution, and $\Phi$ denotes the cumulative normal distribution function. Under the assumption of lognormality, the standard deviation is estimated with the following relationship [41]:

$$
\sigma=\sqrt{2} \cdot \Phi^{-1}\left(\frac{\pi+1}{2}\right)
$$

where $\pi$ is the Gini coefficient. Historical observations of the Gini coefficient are available for most countries from the World Bank, and are applied in this study to parameterize income inequality in the base-year. For countries lacking historical observations, we utilize a regional average.

Assuming the bottom four national income quintiles incorporating both urban and rural residents split the income evenly (i.e., everything but the GDP represented by the top quintile), we identify the average rural per capita GDP using the value of the Lorenz curve at the top income quintile:

$$
g_{r}=g_{n} \cdot \frac{L(x)}{x}
$$

where $x=0.8$ for the top income quintile. Once calculated, the rural per capita GDP is 
inserted into (1) to calculate the corresponding urban-level. Without further information on the sub-national distribution of income-levels ${ }^{2}$, we assume that the identified urban and rural per capita GDPs do not vary across grid-cells within countries.

In future years, national Gini coefficients are assumed to converge or diverge towards the qualitative inequality trends implicit in the scenario narratives (Table 1, main text). For example, in SSP1 and 5, inclusive development leads to widespread reductions in inequalities, and we reflect these conditions by having Gini coefficients converge towards a relatively low value of 0.29 by the end of the century (close to the level currently seen in Sweden and Denmark). Conversely, in SSP 3 and 4, which contain explicit narratives describing increased inequality, we set convergent values to 0.6 (close to the level currently seen in South Africa). To account for institutional inertia, we analyzed decadal observations for OECD countries to identify a distribution of historical rates of change and then set a maximum rate of inequality change to the 50 th percentile value $(0.15 \%$ per year $)$.

The model formulation requires estimates of the urban and rural Gini coefficient. Empirical studies show that differences between urban and rural income inequality exist in countries such as India, where in the 90 s, the rural Gini was typically about $20 \%$ less than the urban Gini [74]. In China, the urban and rural Gini coefficients from 1978 to 2002 trace a similar path [75]. Without detailed information on the historical trajectories of all countries we simplify the analysis by assuming that the urban and rural population groups display equivalent Gini coefficients, and identify a common value that ensures consistency with the national-level and the decomposed average income levels. The Theil index is an alternative inequality metric that can be readily decomposed into urban and rural com-

\footnotetext{
${ }^{2}$ The GECON dataset provides sub-national spatial information on the distribution of GDP [73]. Calculating gridded per capita GDP with the GECON and SSP population datasets results in extreme outcomes because some rural areas with low population have high industrial output. The spatial GDP in GECON is a better metric for production intensity, not consumption in the municipal sector.
} 
ponents [76]. Under income distribution lognormality, the Theil index is approximately equal to half the variance $v=\sigma^{2}$ [77]. Based on the Theil decomposition described in [76], we obtain the following relationship between the national income standard deviation $\left(v_{n}\right)$ and the urban-rural value $\left(v_{u r}\right)$ :

$$
v_{u r}=v_{n}+2 \cdot\{u \cdot \ln (\kappa)-\ln [1+u \cdot(\kappa-1)]\}
$$

where $\kappa$ is the urban-rural average income ratio. Corresponding urban-rural Gini coefficients can be identified with (A.3). Following the analysis in [47], the urban-rural average income ratio is assumed to converge over time at the scenario-specific rates in Table 1 of the main text. This feature allows the simulation framework to incorporate expected income effects implicit in the scenario narrative, such as inclusive development strategies that reduce income inequalities across a population.

\section{Software/data availability}

The gridded municipal water demand scenarios described in this paper are available upon request from the corresponding author (S.C. Parkinson: scp@uvic.ca).

\section{Acknowledgements}

The Coupled Model Intercomparison Project Phase 5 (CMIP5) and the Inter-Sectoral Impact Model Intercomparison Project (ISIMIP) is acknowledged for providing the global climate model output for this study. SCP was supported in part by a post-graduate scholarship from the Natural Sciences \& Engineering Research Council of Canada. ND acknowledges with thanks partial funding of this project by the Deanship of Scientific Research (DSR), King Abdulaziz University, Jeddah, under grant no. (1-135-36-HiCi). 


\section{References}

[1] C. J. Vörösmarty, P. Green, J. Salisbury, R. B. Lammers, Global water resources: Vulnerability from climate change and population growth, Science 289 (5477) (2000) 284-288.

[2] J. Alcamo, P. Döll, T. Henrichs, F. Kaspar, B. Lehner, T. Rösch, S. Siebert, Development and testing of the WaterGAP 2 global model of water use and availability, Hydrological Sciences Journal 48 (3) (2003) 317-337.

[3] N. W. Arnell, D. P. van Vuuren, M. Isaac, The implications of climate policy for the impacts of climate change on global water resources, Global Environmental Change 21 (2) (2011) 592-603.

[4] Y. Wada, L. van Beek, D. Viviroli, H. H. Dürr, R. Weingartner, M. F. Bierkens, Global monthly water stress: 2 . Water demand and severity of water stress, Water Resources Research 47 (7).

[5] I. Haddeland, J. Heinke, H. Biemans, S. Eisner, M. Flörke, N. Hanasaki, M. Konzmann, F. Ludwig, Y. Masaki, J. Schewe, et al., Global water resources affected by human interventions and climate change, Proceedings of the National Academy of Sciences 111 (9) (2014) 3251-3256.

[6] M. Hejazi, J. Edmonds, L. Clarke, P. Kyle, E. Davies, V. Chaturvedi, M. Wise, P. Patel, J. Eom, K. Calvin, Integrated assessment of global water scarcity over the $21 \mathrm{st}$ century under multiple climate change mitigation policies, Hydrology and Earth System Sciences 18 (8) (2014) 2859-2883.

[7] G. van Drecht, A. Bouwman, J. Harrison, J. Knoop, Global nitrogen and phosphate in urban wastewater for the period 1970 to 2050, Global Biogeochemical Cycles 23 (4). 
[8] R. I. McDonald, K. Weber, J. Padowski, M. Flörke, C. Schneider, P. A. Green, T. Gleeson, S. Eckman, B. Lehner, D. Balk, et al., Water on an urban planet: Urbanization and the reach of urban water infrastructure, Global Environmental Change 27 (2014) 96-105.

[9] M. Flörke, E. Kynast, I. Bärlund, S. Eisner, F. Wimmer, J. Alcamo, Domestic and industrial water uses of the past 60 years as a mirror of socio-economic development: A global simulation study, Global Environmental Change 23 (1) (2013) 144-156.

[10] M. Hejazi, J. Edmonds, L. Clarke, P. Kyle, E. Davies, V. Chaturvedi, M. Wise, P. Patel, J. Eom, K. Calvin, et al., Long-term global water projections using six socioeconomic scenarios in an integrated assessment modeling framework, Technological Forecasting and Social Change 81 (2014) 205-226.

[11] N. Hanasaki, S. Fujimori, T. Yamamoto, S. Yoshikawa, Y. Masaki, Y. Hijioka, M. Kainuma, Y. Kanamori, T. Masui, K. Takahashi, et al., A global water scarcity assessment under shared socio-economic pathways-Part 1: Water use, Hydrology and Earth System Sciences 17 (7) (2013) 2375-2391.

[12] C. W. Howe, F. P. Linaweaver, The impact of price on residential water demand and its relation to system design and price structure, Water Resources Research 3 (1) (1967) 13-32.

[13] P. W. Mayer, W. B. DeOreo, E. M. Opitz, J. C. Kiefer, W. Y. Davis, B. Dziegielewski, J. O. Nelson, Residential end uses of water, AWWA Research Foundation and American Water Works Association Denver, CO, 1999.

[14] J. Thompson, Drawers of Water II: 30 years of change in domestic water use \& environmental health in east Africa. Summary, Vol. 3, IIED, 2001. 
[15] L. A. House-Peters, H. Chang, Urban water demand modeling: Review of concepts, methods, and organizing principles, Water Resources Research 47 (5).

[16] S. J. Cohen, Projected increases in municipal water use in the great lakes region due to $\mathrm{CO} 2$ induced climatic change, JAWRA Journal of the American Water Resources Association 23 (1) (1987) 91-101.

[17] G. Dandy, T. Nguyen, C. Davies, Estimating residential water demand in the presence of free allowances, Land Economics (1997) 125-139.

[18] T. Downing, R. Butterfield, B. Edmonds, J. Knox, S. Moss, B. Piper, E. Weatherhead, Climate change and the demand for water, DETR.

[19] D. S. Gutzler, J. S. Nims, Interannual variability of water demand and summer climate in Albuquerque, New Mexico, Journal of Applied Meteorology 44 (12) (2005) $1777-1787$.

[20] T. C. Brown, R. Foti, J. A. Ramirez, Projected freshwater withdrawals in the United States under a changing climate, Water Resources Research 49 (3) (2013) 12591276.

[21] A. Thebo, P. Drechsel, E. Lambin, Global assessment of urban and peri-urban agriculture: irrigated and rainfed croplands, Environmental Research Letters 9 (11) (2014) 114002.

[22] M. G. Badami, N. Ramankutty, Urban agriculture and food security: A critique based on an assessment of urban land constraints, Global Food Security 4 (2015) 8-15.

[23] P. Gober, A. Brazel, R. Quay, S. Myint, S. Grossman-Clarke, A. Miller, S. Rossi, Using watered landscapes to manipulate urban heat island effects: how much water 
will it take to cool phoenix?, Journal of the American Planning Association 76 (1) (2009) 109-121.

[24] B. C. O’Neill, E. Kriegler, K. Riahi, K. L. Ebi, S. Hallegatte, T. R. Carter, R. Mathur, D. P. van Vuuren, A new scenario framework for climate change research: the concept of shared socioeconomic pathways, Climatic Change 122 (3) (2014) 387-400.

[25] D. P. van Vuuren, J. Edmonds, M. Kainuma, K. Riahi, A. Thomson, K. Hibbard, G. C. Hurtt, T. Kram, V. Krey, J.-F. Lamarque, et al., The representative concentration pathways: an overview, Climatic Change 109 (2011) 5-31.

[26] FAO, Food and Agriculture Organization of the United Nations, AQUASTAT, http://www.fao.org/nr/water/aquastat/main/index.stm, last accessed: 2014-11-15 (2014).

[27] World Bank, World Bank Indicators, http://data.worldbank.org/indicator, last accessed: 2014-10-11 (2014).

[28] S. H. Kim, M. Hejazi, L. Liu, K. Calvin, L. Clarke, J. Edmonds, P. Kyle, P. Patel, M. Wise, E. Davies, Balancing global water availability and use at basin scale in an integrated assessment model, Climatic Change 136 (2) (2016) 217-231.

[29] V. Krey, Global energy-climate scenarios and models: a review, Wiley Interdisciplinary Reviews: Energy and Environment 3 (4) (2014) 363-383.

[30] D. Laucelli, L. Berardi, O. Giustolisi, Assessing climate change and asset deterioration impacts on water distribution networks: Demand-driven or pressure-driven network modeling?, Environmental Modelling \& Software 37 (2012) 206-216. 
[31] E. H. Beh, G. C. Dandy, H. R. Maier, F. L. Paton, Optimal sequencing of water supply options at the regional scale incorporating alternative water supply sources and multiple objectives, Environmental Modelling \& Software 53 (2014) 137-153.

[32] S. C. Parkinson, N. Djilali, V. Krey, O. Fricko, N. Johnson, Z. Khan, K. Sedraoui, A. H. Almasoud, Impacts of groundwater constraints on Saudi Arabias low-carbon electricity supply strategy, Environmental science \& technology 50 (4) (2016) 16531662.

[33] M. W. Jenkins, J. R. Lund, R. E. Howitt, Using economic loss functions to value urban water scarcity in california, Journal (American Water Works Association) 95 (2) (2003) 58-70.

[34] M. A. Cole, Economic growth and water use, Applied Economics Letters 11 (1) (2004) 1-4.

[35] F. Trieb, H. Müller-Steinhagen, Concentrating solar power for seawater desalination in the Middle East and North Africa, Desalination 220 (1) (2008) 165-183.

[36] Y. Shen, T. Oki, N. Utsumi, S. Kanae, N. Hanasaki, Projection of future world water resources under SRES scenarios: Water withdrawal, Hydrological Sciences Journal 53 (1) (2008) 11-33.

[37] M. Hejazi, J. Edmonds, V. Chaturvedi, E. Davies, J. Eom, Scenarios of global municipal water-use demand projections over the 21st century, Hydrological Sciences Journal 58 (3) (2013) 519-538.

[38] B. Guo, Y. Chen, Y. Shen, W. Li, C. Wu, Spatially explicit estimation of domestic water use in the arid region of northwestern China: 1985-2009, Hydrological Sciences Journal 58 (1) (2013) 162-176. 
[39] X. Cirera, E. Masset, Income distribution trends and future food demand, Philosophical Transactions of the Royal Society B: Biological Sciences 365 (1554) (2010) 2821-2834.

[40] F. Cowell, Measuring inequality, Oxford University Press, 2011.

[41] J. Aitchison, J. A. Brown, The Lognormal Distribution, Cambridge University Press, 1966.

[42] B. J. van Ruijven, D. P. van Vuuren, B. J. de Vries, M. Isaac, J. P. van der Sluijs, P. L. Lucas, P. Balachandra, Model projections for household energy use in India, Energy Policy 39 (12) (2011) 7747-7761.

[43] U. A. Amarasinghe, V. Smakhtin, Global water demand projections: past, present and future., Tech. rep., International Water Management Institute (IWMI) (2014).

[44] A. Young, Inequality, the urban-rural gap and migration, The Quarterly Journal of Economics (2013) qjt025.

[45] I. Koutiva, C. Makropoulos, Modelling domestic water demand: An agent based approach, Environmental Modelling \& Software 79 (2016) 35-54.

[46] R. Koenker, quantreg: Quantile Regression. R package version 4.10 (2007).

[47] A. Grübler, B. O’Neill, K. Riahi, V. Chirkov, A. Goujon, P. Kolp, I. Prommer, S. Scherbov, E. Slentoe, Regional, national, and spatially explicit scenarios of demographic and economic change based on SRES, Technological Forecasting and Social Change 74 (7) (2007) 980-1029.

[48] A. Grübler, Technology and global change, Cambridge University Press, 2003. 
[49] M. Smith, CROPWAT: A computer program for irrigation planning and management, Vol. 46, UN FAO, 1992.

[50] P. Döll, Impact of climate change and variability on irrigation requirements: a global perspective, Climatic change 54 (3) (2002) 269-293.

[51] J. J. Boland, Assessing urban water use and the role of water conservation measures under climate uncertainty, Climatic Change 37 (1) (1997) 157-176.

[52] T. D. Johnson, K. Belitz, A remote sensing approach for estimating the location and rate of urban irrigation in semi-arid climates, Journal of Hydrology 414 (2012) 8698.

[53] E. Domene, D. Saurí, Urbanisation and water consumption: Influencing factors in the metropolitan region of Barcelona, Urban Studies 43 (9) (2006) 1605-1623.

[54] L. Fan, G. Liu, F. Wang, V. Geissen, C. J. Ritsema, Factors affecting domestic water consumption in rural households upon access to improved water supply: Insights from the Wei River Basin, China, PloS one 8 (8) (2013) e71977.

[55] A. K. Marinoski, A. S. Vieira, A. S. Silva, E. Ghisi, Water end-uses in low-income houses in Southern Brazil, Water 6 (7) (2014) 1985-1999.

[56] H. H. Zhang, D. F. Brown, Understanding urban residential water use in Beijing and Tianjin, China, Habitat International 29 (3) (2005) 469-491.

[57] W. Farmer, K. Strzepek, C. A. Schlosser, P. Droogers, X. Gao, A method for calculating reference evapotranspiration on daily time scales, Tech. rep., MIT Joint Program on the Science and Policy of Global Change (2011). 
[58] M. Isaac, D. P. van Vuuren, Modeling global residential sector energy demand for heating and air conditioning in the context of climate change, Energy Policy 37 (2) (2009) 507-521.

[59] M. S. Johnson, M. J. Lathuillière, T. R. Tooke, N. C. Coops, Attenuation of urban agricultural production potential and crop water footprint due to shading from buildings and trees, Environmental Research Letters 10 (6) (2015) 064007.

[60] B. C. O`Neill, E. Kriegler, K. L. Ebi, E. Kemp-Benedict, K. Riahi, D. S. Rothman, B. J. van Ruijven, D. P. van Vuuren, J. Birkmann, K. Kok, et al., The roads ahead: Narratives for shared socioeconomic pathways describing world futures in the $21 \mathrm{st}$ century, Global Environmental Change.

[61] K. Samir, W. Lutz, The human core of the shared socioeconomic pathways: Population scenarios by age, sex and level of education for all countries to 2100, Global Environmental Change.

[62] L. Jiang, B. C. O’Neill, Urbanization projections for the shared socioeconomic pathways, Global Environmental Change.

[63] R. Dellink, J. Chateau, E. Lanzi, B. Magné, Long-term economic growth projections in the shared socioeconomic pathways, Global Environmental Change.

[64] B. Jones, B. O'Neill, Spatial population scenarios consistent with the sharedsocioeconomic pathways, In Preparation (2015) 1-10.

[65] B. Jones, Assessment of a gravity-based approach to constructing future spatial population scenarios, Journal of Population Research 31 (1) (2014) 71-95.

[66] K. E. Taylor, R. J. Stouffer, G. A. Meehl, An overview of CMIP5 and the experiment design, Bulletin of the American Meteorological Society 93 (4) (2012) 485-498. 
[67] S. Hempel, K. Frieler, L. Warszawski, J. Schewe, F. Piontek, A trend-preserving bias correction-the ISI-MIP approach, Earth System Dynamics 4 (2) (2013) 219-236.

[68] ISI-MIP, ISI-MIP database, http://esg.pik-potsdam.de, last accessed: 2015-03-10 (2014).

[69] A. Kay, A. Rudd, H. Davies, E. Kendon, R. Jones, Use of very high resolution climate model data for hydrological modelling: Baseline performance and future flood changes, Climatic Change 133 (2) (2015) 193-208.

[70] M. Flörke, S. Eisner, N. Hanasaki, Y. Masaki, Y. Wada, M. Bierkens, A multi-model ensemble for identifying future water stress hotspots, in: Impacts World 2013, International Conference on Climate Change Effects, 2013.

[71] K. Riahi, S. Rao, V. Krey, C. Cho, V. Chirkov, G. Fischer, G. Kindermann, N. Nakicenovic, P. Rafaj, RCP 8.5: A scenario of comparatively high greenhouse gas emissions, Climatic Change 109 (1-2) (2011) 33-57.

[72] D. P. van Vuuren, E. Stehfest, M. G. den Elzen, T. Kram, J. van Vliet, S. Deetman, M. Isaac, K. K. Goldewijk, A. Hof, A. M. Beltran, et al., RCP2. 6: Exploring the possibility to keep global mean temperature increase below 2 degrees C, Climatic Change 109 (1-2) (2011) 95-116.

[73] W. Nordhaus, Q. Azam, D. Corderi, K. Hood, N. M. Victor, M. Mohammed, A. Miltner, J. Weiss, The G-Econ database on gridded output: Methods and data, Yale University, New Haven.

[74] A. Sen, Poverty and inequality in India: Getting closer to the truth., New Delhi: Macmillan, 2003. 
817 [75] L. Shi, Changes in income inequality in China in the last three decades (2010).

${ }_{818}$ [76] R. Kanbur, J. Zhuang, Urbanization and inequality in Asia, Asian Development Review 30 (1) (2013) 131-147.

[77] G. H. Griffiths, E. William, Pareto-Lognormal Income Distributions: Inequality and Poverty Measures, Estimation and Performance, Tech. rep., The University of Melbourne (2012). 